$11-1996$

\title{
Permeability of Microporous Carbon Preforms
}

S. K. Datta

Thermal Treatment Center, Inc.

N. Simhai

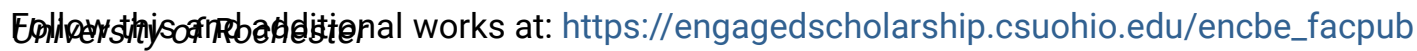

sureflarafthe Newariarials Science and Engineering Commons

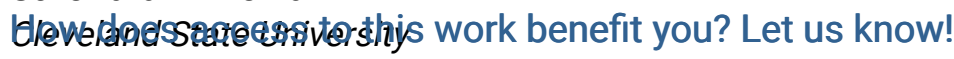

Publisher's Statement

Eqeveriand State Ansm International. This paper was published in Metallurgical and Materials

Transactions A: Physical Metallurgy and Materials Science, Vol. 27, Issue 11, pp. 3669-3674 and M. nimathavailable as an electronic reprint with the permission of ASM International. One print or NYMA NASA Lewis Group, Inc. distribution to multiple locations via electronic or other means, duplications of any material in this paper for a fee or for commercial purposes, or modification of the content of this paper are prohibited.

Available on publisher's site at: http://www.springerlink.com/content/f26t1n308r377683/.

\section{Original Citation}

Datta, SK; Simhai, N; Tewari, SN; Gatica, JE; Singh, M. (1996). Permeability of Microporous Carbon Preforms. Metallurgical and Materials Transactions A: Physical Metallurgy and Materials Science 27, 3669-3674.

\section{Repository Citation}

Datta, S. K.; Simhai, N.; Tewari, Surendra N.; Gatica, Jorge E.; and Singh, M., "Permeability of Microporous Carbon Preforms" (1996). Chemical \& Biomedical Engineering Faculty Publications. 18.

https://engagedscholarship.csuohio.edu/encbe_facpub/18

This Article is brought to you for free and open access by the Chemical \& Biomedical Engineering Department at EngagedScholarship@CSU. It has been accepted for inclusion in Chemical \& Biomedical Engineering Faculty Publications by an authorized administrator of EngagedScholarship@CSU. For more information, please contact library.es@csuohio.edu. 


\title{
Permeability of Microporous Carbon Preforms
}

\author{
S.K. DATTA, N. SIMHAI, S.N. TEWARI, J.E. GATICA, and M. SINGH
}

The permeability of microporous amorphous carbon preforms with varying pore size and pore distributions has been experimentally examined. The porous structures have been characterized by mercury porosimetry and by quantitative metallography of pressure-infiltration-cast metal matrix composites based on the carbon preforms. The permeability shows a linear correlation with the fraction porosity and the square of the pore diameter.

\section{INTRODUCTION}

PERMEABILITY is an overall transport parameter widely used in macroscopic descriptions of fluid flow through porous structures in many engineering applications, such as flow of interdendritic melt during solidification, ${ }^{[1]}$ infiltration of metallic melts through particulate or fibrous ceramic preforms, ${ }^{[2]}$ and resin impregnation during polymer composite fabrication. ${ }^{[3]}$ For a Boussinesq's fluid, Darcy's law $^{[4]}$ gives

$$
\begin{aligned}
\rho_{f}^{0} \frac{\partial \mathbf{u}}{\partial t} & =-\nabla p-\frac{\mu_{f}}{\kappa} \mathbf{u}-\rho_{f}^{0}\left[\beta_{T}\left(T-T^{0}\right)\right. \\
& \left.+\beta_{C}\left(C-C^{0}\right)\right] \mathbf{g}
\end{aligned}
$$

where $\kappa$ is the (porous) medium permeability. This parameter allows one to treat the fluid-solid system as a quasicontinous medium. A number of empirical relationships have been derived for packed ${ }^{[5]}$ and fibrous beds, ${ }^{[6]}$ and bundles of aligned fibers, ${ }^{[7]}$ including correction factors for nonspherical shapes and misalignment of the fibers, as well. There is, however, no reliable equation ${ }^{[8]}$ that could predict the permeability for a given microporous structure. The approach, therefore, has been to extract this value from experimental measurements. Assuming steady-state conditions and ignoring buoyancy effects, for unidirectional flow, Darcy's relationship becomes

$$
u_{z}=-\frac{\kappa}{\mu_{f}} \frac{\partial p}{\partial z}
$$

which can be easily solved, assuming a linear dependence for the pressure.

$$
z^{2}=2 \frac{\langle\kappa\rangle}{\mu_{f}} \Delta p t
$$

or

S.K. DATTA, formerly Graduate Student, Chemical Engineering Department, Cleveland State University, is Project Engineer, Thermal Treatment Center, Inc., Wickliffe, OH 44092. N. SIMHAI, formerly a Student at Charles F. Brush High School, Lyndhurst, OH 44124, is currently a Student at Dept. of Chemistry, University of Rochester, Rochester, NY 14627. S.N. TEWARI, Professor, and J.E. GATICA, Assistant Professor, are with the Chemical Engineering Department, Cleveland State University, Cleveland, OH 44115. M. SINGH, Senior Research Engineer, is with NYMA, Inc., Lewis Research Center Group, Cleveland, OH 44135.

Manuscript submitted February 1, 1996.

$$
\begin{aligned}
v_{\text {superficial }} & =\varepsilon v_{\text {infiltration }} \\
& =\frac{\langle\kappa\rangle}{\mu_{f}} \frac{\Delta p}{z}
\end{aligned}
$$

where

$$
\frac{1}{\langle\kappa\rangle} \approx \frac{1}{z} \int_{0}^{z} \frac{1}{\kappa} d z
$$

The average permeability $\langle\kappa\rangle$, therefore, can be extracted from experimental measurements of flow rate $v s$ applied pressure gradient on a representative sample. Obviously, permeability is expected to depend on the microstructural details of the channels, such as size, shape, volume fraction, and distribution of interconnected porosities. There are two techniques available to characterize porous structures: mercury porosimetry and quantitative metallography. During mercury porosimetry, the porous preform is immersed into a mercury bath and the volume of mercury, intruded into the preform, is measured as a function of applied hydrostatic pressure. This information is then used to obtain the incremental intrusion volume (per unit weight) of the porous specimen as a function of the pore diameter, assuming that the pores are cylindrical in shape. The data can then be processed to determine the pore-size distribution. Knowing the bulk density and the total intruded volume, the skeletal density is determined assuming a continuous porosity, i.e., no isolated pores exist in the specimen. Metallography of the preforms can also be used to obtain a detailed quantitative description of pore volume fraction, as well as pore shape and size distribution. The purpose of this research was to quantitatively examine the interconnected microchannels by these two techniques and identify the microstructural parameters that best describe the experimentally determined permeability through microporous carbon preforms.

\section{RESULTS}

\section{A. Microporous Carbon Preforms}

The microporous amorphous carbon preforms used in this study were made with a mixture of furfuryl alcohol resin, diethylene and triethylene glycols, and $p$-toluene sulfonic acid. This mixture was polymerized to form a porous solid polymer. The solid polymer was then heated slowly up to $970 \mathrm{~K}$ in a flowing argon atmosphere, which resulted in the production of microporous carbon preforms. Pre- 


\section{MICROSTRUCTURE OF MICROPOROUS}

\section{CARBON PREFORM}

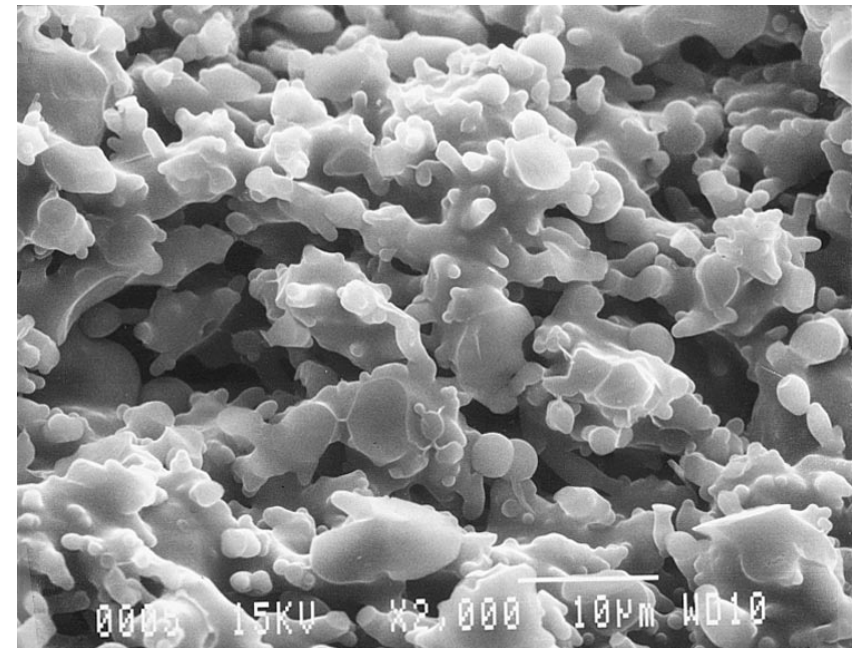

(a)

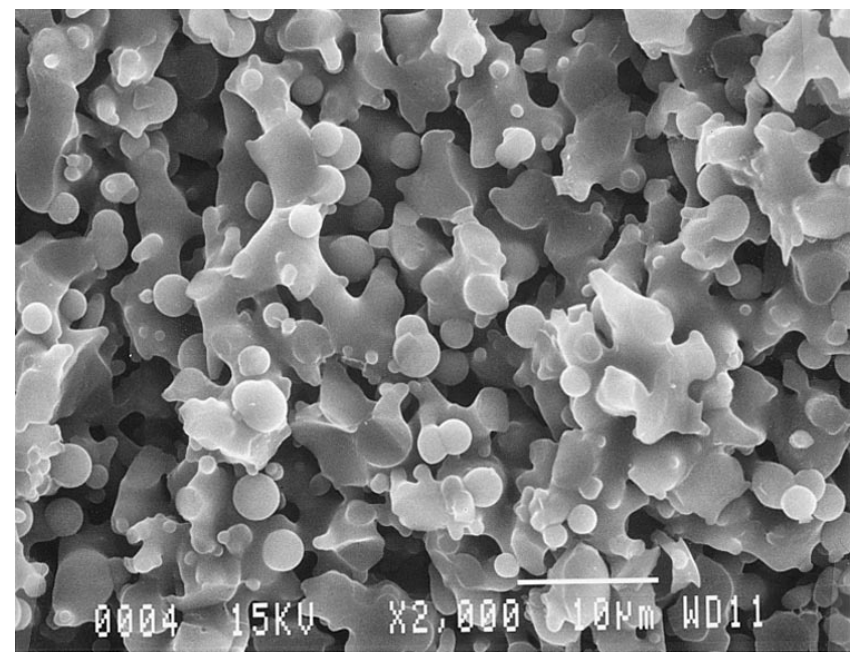

(b)
TYPE “A1”

TYPE “A”

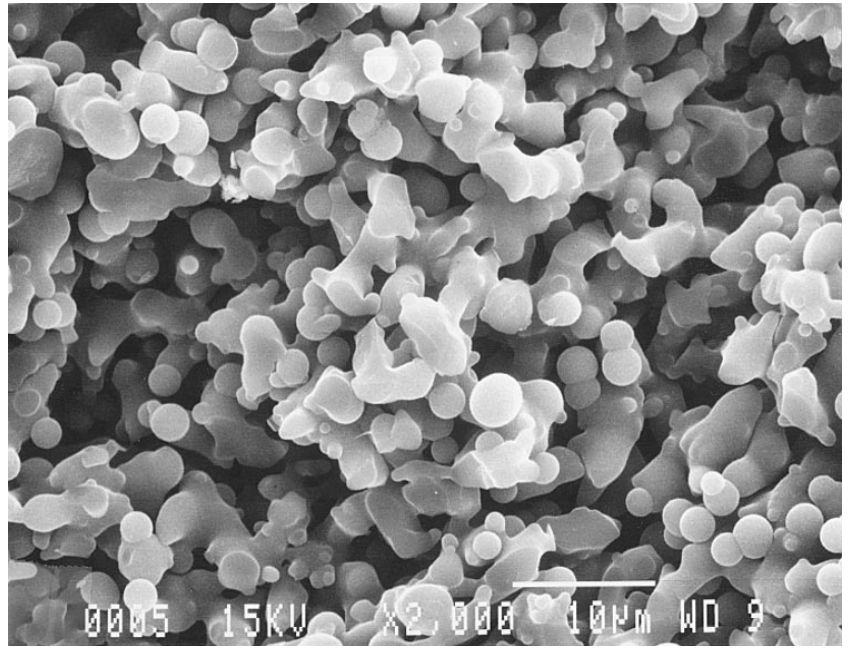

(c)

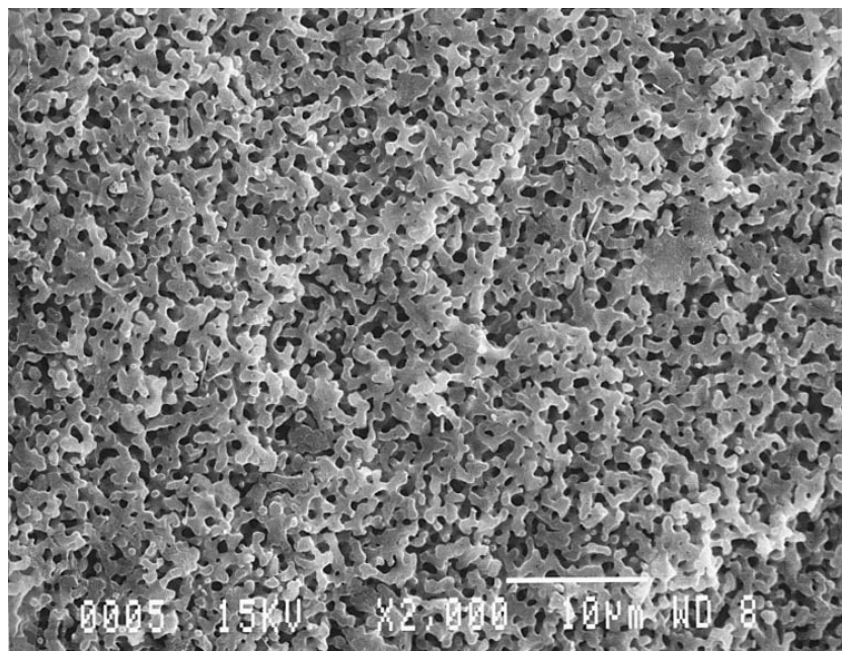

(d)

\section{TYPE “A2”}

Fig. 1-Microstructure of microporous carbon preforms: $(a)$ type A1, $(b)$ type A, $(c)$ type B, and $(d)$ type A2.

forms with a range of pore sizes were obtained by varying the composition of the organic mixture. Further details of the preform fabrication are provided elsewhere. ${ }^{\left[{ }^{[9}\right.}$ Figure 1 shows typical microstructures of the four types of microporous carbon preforms used in this study. They are types "A1," "A," “B,', and "A2,', with decreasing pore size. Their microstructures consist of carbon struts which are bridged together and the interstrut continuous channels of microporosity. The three-dimensional (3-D) network of interconnected pores does not appear to have any anisotropy.

\section{B. Mercury Porosimetry}

Figure 2(b) shows a typical percent intrusion-volume vs pore-diameter curve, determined with a Micromeritics
Auto-Pore 9200 porosimeter. The specimens used were cylindrical, with a diameter of $1.4 \mathrm{~cm}$ and a length of $1.2 \mathrm{~cm}$. The data shown in Figure 2(b) correspond to a type A preform; this can be used to determine the pore-size distribution, as shown in Figure 2(a). This specimen shows a narrow unimodal pore-size distribution. Statistical analysis of the data was carried out to estimate an intrusion volumebased median and average pore diameters. Table 1 compiles the mercury porosimetry data for the four microporous amorphous carbon specimens examined in this study. It also lists the bulk density, skeletal density, and the volume fraction porosity $\varepsilon$. A comparison between the skeletal density, 1.48 to $1.51 \mathrm{~g} \mathrm{~cm}^{-3}$, and the literature reported density of glassy carbon, $1.5 \mathrm{~g} \mathrm{~cm}^{-3}$, shows that the pores in these preforms are interconnected. In the presence of isolated pores, the skeletal density deduced from mercury porosi- 

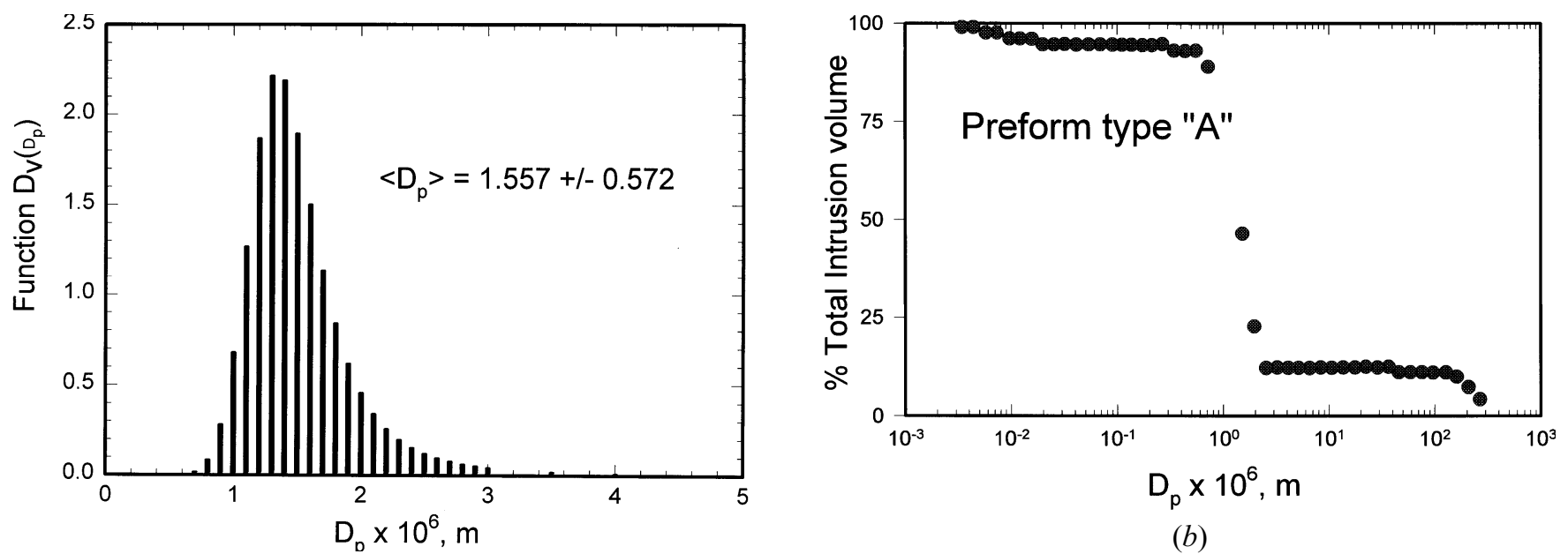

(a)

Fig. 2-Porosimetry determinations for preform type A: $(a)$ pore size distribution function and $(b)$ intrusion curve.

Table I. Mercury Porosimetry Data for Microporous Carbon Specimens

\begin{tabular}{lcccc}
\hline & Type & Type & Type & Type \\
Characteristics & A1 & A & B & A2 \\
\hline Median pore diameter $(\mu \mathrm{m})$ & 2.17 & 1.42 & 1.25 & 0.45 \\
Average pore diameter $(\mu \mathrm{m})$ & 2.40 & 1.56 & 1.49 & 0.51 \\
Fraction porosity & 0.50 & 0.48 & 0.53 & 0.45 \\
Bulk density $\left(\mathrm{g} \mathrm{cm}^{-3}\right)$ & 0.75 & 0.77 & 0.70 & 0.82 \\
Skeletal density $\left(\mathrm{g} \mathrm{cm}^{-3}\right)$ & 1.48 & 1.48 & 1.51 & 1.48 \\
\hline
\end{tabular}

metry would be less than the actual density value of the solid phase of the preform.

\section{Quantitative Image Analysis}

The microporous carbon specimens were pressure infiltrated by a copper-silicon-chromium alloy melt to obtain composite specimens which had adequate contrast for quantitative image analysis of pores. Melt infiltration was carried out at about $1370 \mathrm{~K}$ by the help of 500 psi argon gas. Typical backscattered secondary electron images from the pressure-infiltration cast composite specimens, from type A1, A, B, and A2 carbon preforms, are shown in Figure 3. In these figures, the bright regions represent the metallic matrix, the gray regions represent the carbon struts, and the black regions (indicated by an arrow) are the uninfiltrated voids. The preform types A1, A, and B were reasonably well infiltrated; but type A2, with the smallest pore size, contained the largest fraction of uninfiltrated voids. Four to five such backscattered scanning electron micrographs (SEM) were used for quantitative image analysis. The infiltrated region and the uninfiltrated voids were counted together as pores for the purpose of image analysis. Because of the interconnectivity of the channels, the metallic matrix and uninfiltrated voids in the pressure cast microstructures were counted together to represent the pores originally present in the preforms. The pore hydraulic diameter $D_{p, H}$, reported in Table II, was obtained from the cross-sectional area occupied by the metal and void regions and the cu- mulative perimeter of the carbon struts. Similarly, the carbon strut hydraulic diameter $D_{s, H}$ was obtained by using the average area and perimeter of the carbon struts.

\section{Permeability Determinations}

Water $\left(\mu \approx 9.62 \times 10^{-10} \mathrm{MPa}\right.$ s) flow rates through the preforms under varying pressure gradients were measured at room temperature in a permeameter, shown schematically in Figure 4(a). Cylindrical specimens, $0.8 \mathrm{~cm}$ in diameter and 2-cm long, were used. Figure 4(b) shows experimental data for the four different preforms; the goodness of fit of linear regression results indicate the applicability of Darcy's law. Therefore, the slopes of the linear fluid velocity vs pressure gradient plots (Eq. [3]), were used to obtain the permeability of the microporous preforms. Replicate experiments were performed and excellent reproducibility was found; for instance, the four sets of data indicated by filled symbols in Figure 4 illustrate the reproducibility verified for type A1 specimens. For the other three types, only one permeability measurement was carried out. A summary of the permeability determinations is presented in Table III.

\section{DISCUSSION}

A dimensional analysis of Eq. [1] suggests that the permeability of microporous preforms should be proportional to the square of a characteristic length $d$. Here, the characteristic length would be an overall parameter that would take into account the pore shape and size distribution of a tortuous 3-D network or interconnected channels. As indicated by the Carman-Kozeny equation, ${ }^{[8]} \kappa=d^{2} \varepsilon / 32$, it is also reasonable to propose a proportionality between permeability and the fraction porosity $\varepsilon$. Let us examine this hypothesis with three different types of length scales: the average and the median pore diameters obtained from the mercury porosimetry and the hydraulic diameters obtained from the quantitative metallography of the infiltrated specimens. Figure 5 shows the preforms permeabilities plotted against the three characteristic diameters. Linear correlations, 


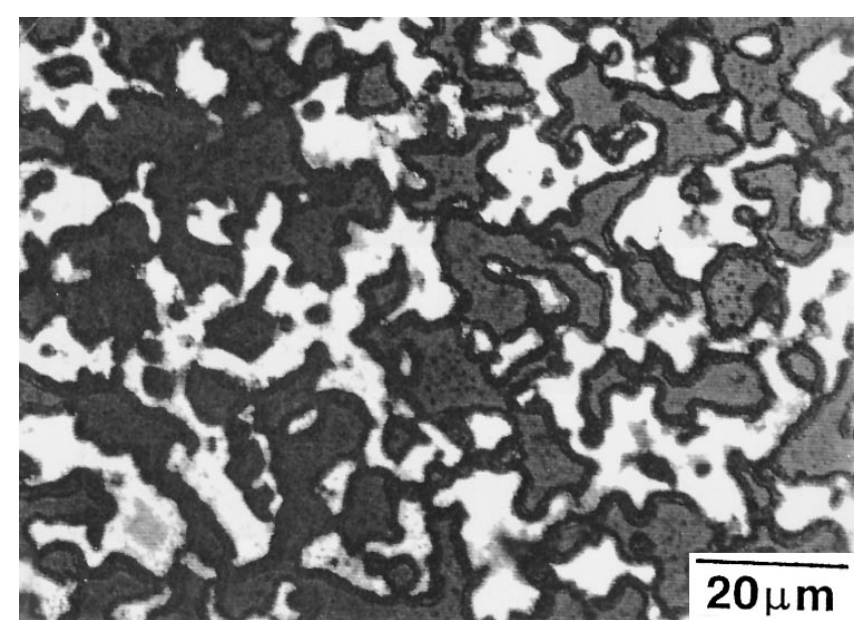

(a) TYPE "A1"

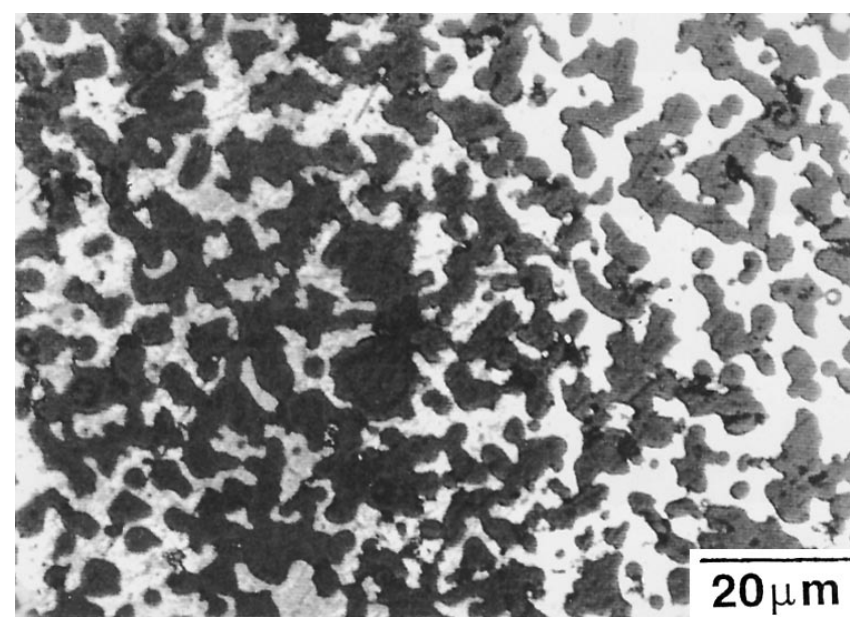

(b)
TYPE "A"

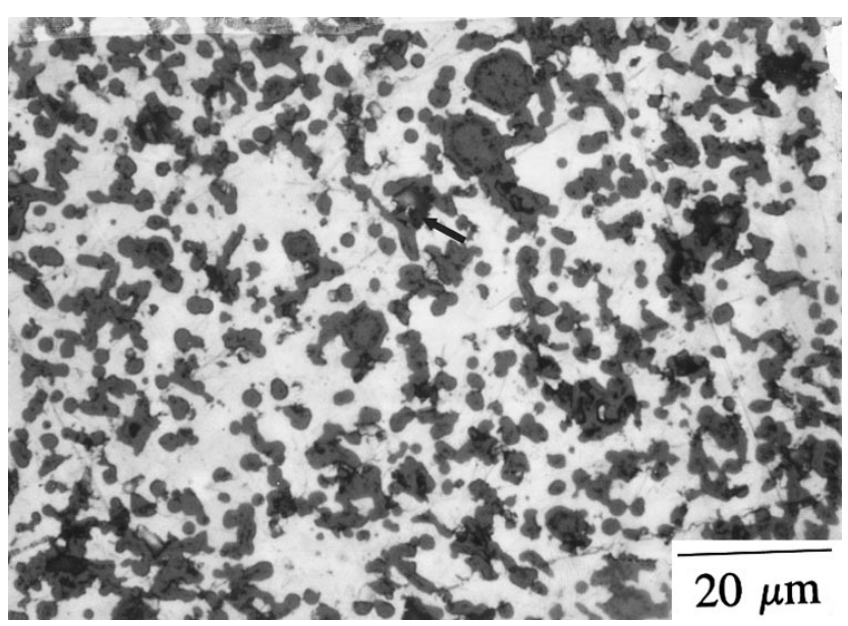

(c)

$$
\text { TYPE "B" }
$$

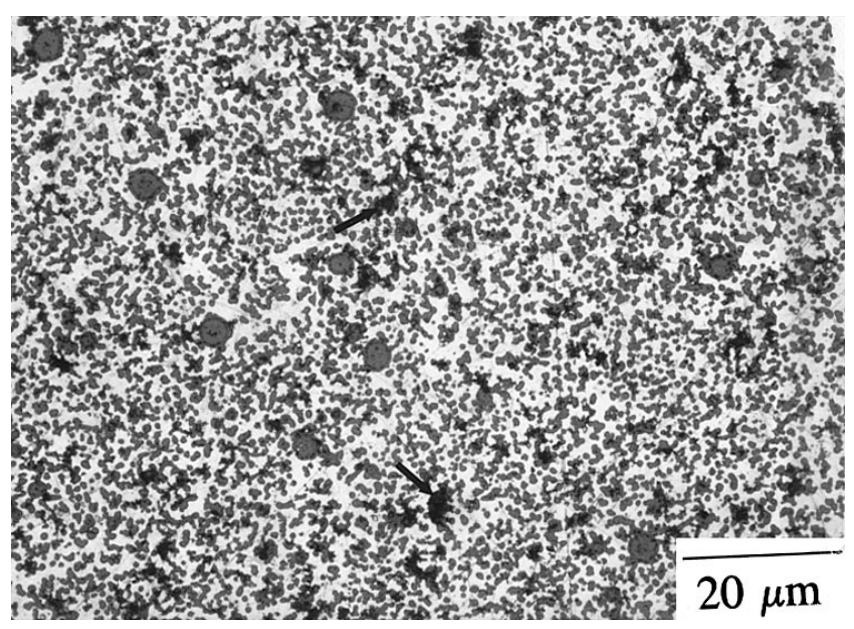

(d)

\section{TYPE “A2”}

Fig. 3-Microstructure of pressure-infiltrated microporous carbon preforms: $(a)$ type A1, $(b)$ type A, $(c)$ type B, and $(d)$ type A2.

Table II. Microstructural Characterization of the Pressure Infiltrated $\mathrm{Cu} / \mathrm{C}$ Composites

\begin{tabular}{lllll}
\hline Characteristics & Type A1 & Type A & Type B & Type A2 \\
\hline $\begin{array}{l}\text { Area fraction (pores) } \\
\text { Hydraulic strut diameter }\end{array}$ & $1.87 \mathrm{pct}$ & $4.80 \mathrm{pct}$ & $4.36 \mathrm{pct}$ & $14.13 \mathrm{pct}$ \\
$\begin{array}{l}(\mu \mathrm{m}) \\
\begin{array}{l}\text { Hydraulic pore diameter } \\
(\mu \mathrm{m})\end{array}\end{array}$ & 5.11 & 4.39 & 3.15 & 2.57 \\
\hline
\end{tabular}

with approximate slopes $1 / 51,1 / 63$, and $1 / 202$, were found for the average, median, and hydraulic diameters, respectively. The linear dependence shown by the porosimetry-extracted diameters correlates satisfactorily with a modified form of the Carman-Kozeny equation, $\kappa=d^{2} \varepsilon / 32 t$, with tortuosity factors $t$ ranging from 1.5 to 2.0 , which fall within the experimental range reported for 3-D porous networks. The results found for the characteristic length obtained from metallographic analyses, on the other hand, do not show the same goodness of fit (an approximate standard deviation of $20 \mathrm{pct}$ ) and suggest an abnormally high tortuosity factor $(\sim 6.5)$.

The hydraulic radius was based on the perimeter and area measurements on one cross section, i.e., the " $\mathrm{X}$ " and " $\mathrm{Y}$ " dimensions on a surface. Therefore, it does not account for the 3-D nature of the porous network in the " $Z$ " (depth) direction. This may be the reason why the metallographically determined hydraulic diameter cannot to be used to characterize the permeability. Under the application of an external pressure, the fluid flow through a microporous preform will be dictated by the size distribution of the interconnecting channels. This hypothesis can be further verified by attempting an alternative correlation with metallographic measurements. For packed beds made of spherical particles, the permeability has been found ${ }^{[5]}$ to depend on the packing characteristic diameter $D$ and the bed void fraction. Such a functionality, referred to as the Ergun equation, $\kappa=D^{2} \varepsilon^{3} / 150(1-\varepsilon)^{2}$, can be investigated here with the carbon struts being considered as packing particles whose characteristic dimension is $D_{s, H}$. Figure 6 shows a plot of the permeability against a combined relationship between the struts' characteristic dimensions and the preforms' porosities. The data seem to correlate linearly with an approximate slope of $1 / 314$. Although the data do not show the wide scattering observed for the pores' hydraulic diameter $D_{p, H}$, the slope is only half of the classical Ergun 


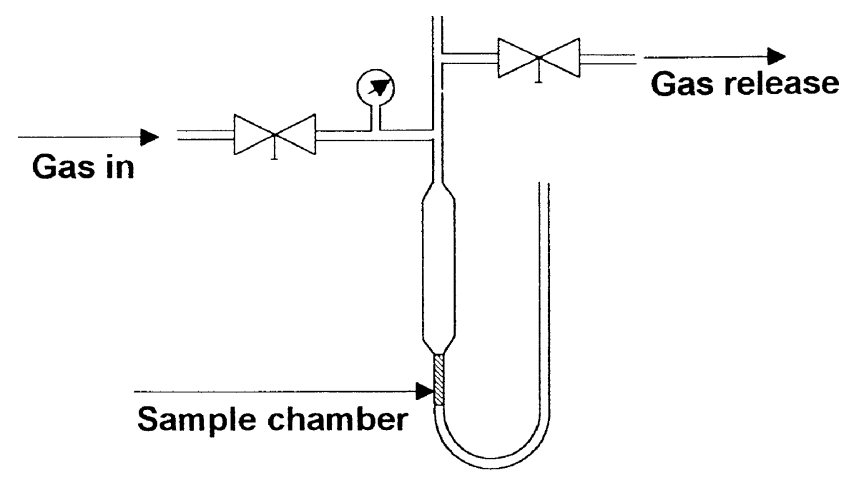

Experimental Setup of permeability

(a)

PERMEABILITY OF MICROPOROUS CARBON PREFORMS

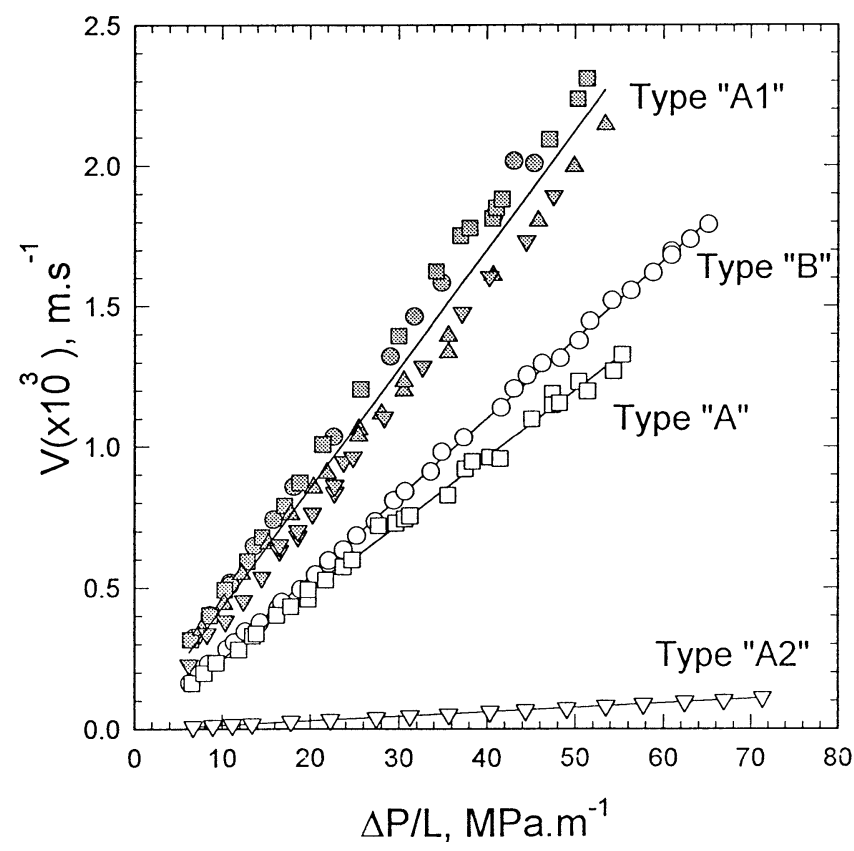

(b)

Fig. 4-Permeability determinations: (a) experimental permeameter assembly and $(b)$ typical permeation determinations.

correlation (1/150). This also indicates that the predictions based on the hydraulic strut diameter would be much higher than the experimental permeability determinations, i.e., the dimension not accounted for in the measurements plays a significant role in infiltration phenomena. Therefore, results found for packed beds cannot be extended to a porous body containing a 3-D channel network of varying cross sections.

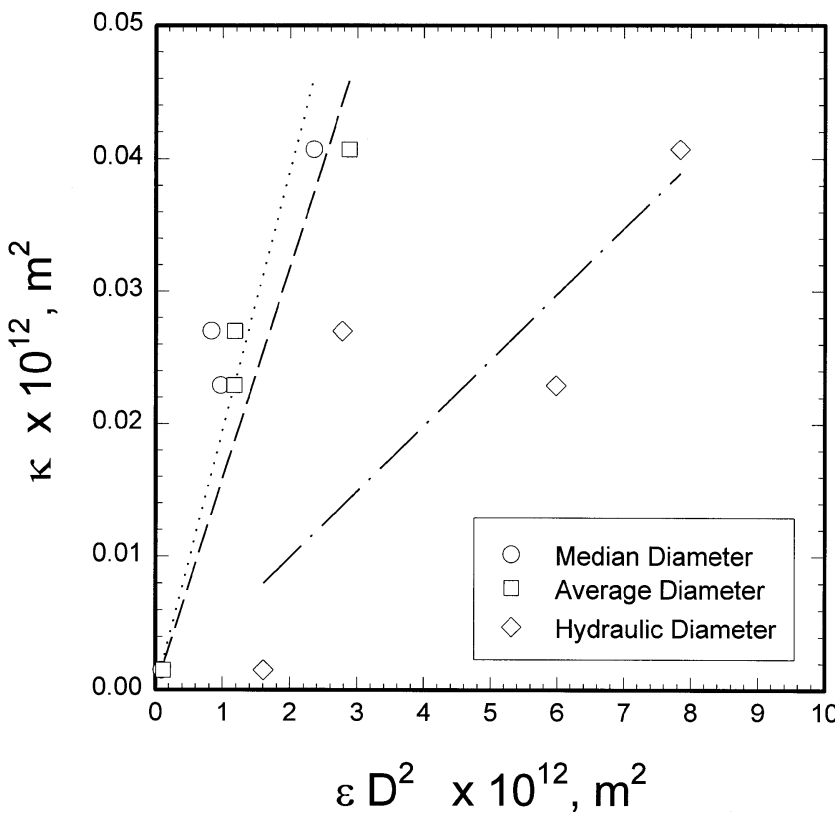

Fig. 5-Correlation between permeability and structure according to the Carman-Kozeny equation.

\section{ERGUN EQUATION CORRELATION}

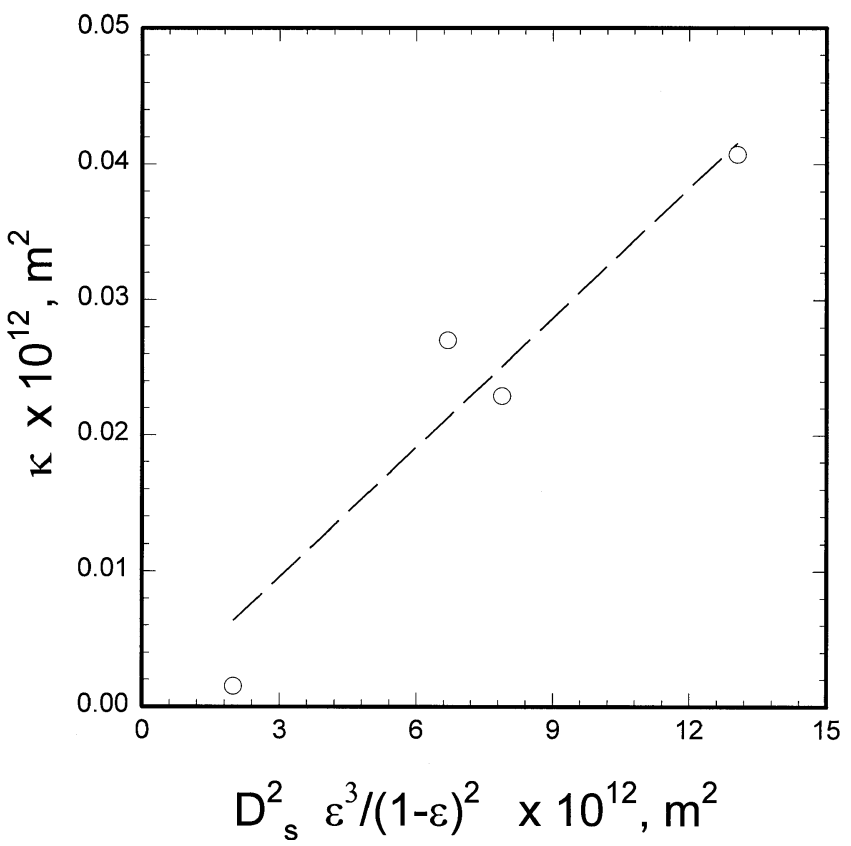

Fig. 6-Correlation between permeability and structure according to the Ergun equation.

The hydraulic determinations, on the other hand, might be

Table III. Permeability Analysis of Porous Carbon Preforms

\begin{tabular}{lcccc}
\hline Characteristics & Type A1 & Type A & Type B & Type A2 \\
\hline Permeability $\times 10^{-14}\left(\mathrm{~m}^{2}\right)$ & $4.07 \pm 0.08$ & $2.29 \pm 0.03$ & $2.70 \pm 0.012$ & $0.15 \pm 0.001$ \\
\hline
\end{tabular}


the suitable length scales for porous bodies with a uniform cross section.

\section{CONCLUSIONS}

Different length scales were examined in this study, including the average and median pore diameters (determined by mercury porosimetry) and the hydraulic pore and strut diameters (determined by cross-sectional quantitative metallography). Only the porosimetry determined diameters appear suitable to describe the permeability of microporous preforms containing three-dimensional networks of interconnected pores. The permeability appears to follow satisfactorily a modified Carman-Kozeny relationship, i.e., it is proportional to the fraction porosity and the square of the pore diameter.

\section{ACKNOWLEDGMENTS}

Appreciation is expressed to Jim Smith for help in quantitative metallography and to the Processing Science and
Technology Branch, NASA-Lewis Research Center, for partially supporting this research.

\section{REFERENCES}

1. D.R. Poirier and S. Ganesan: Mater. Sci. Eng., 1992, vol. A137, pp. 113-23.

2. S. Long, Z. Zhang, and H.M. Flower: Acta Metall. Mater., 1994, vol. 42 (4), pp. 1389-97.

3. A.W. Chan, D.E. Larive, and R.J. Morgan: J. Composite Mater., 1993, vol. 27 (10), pp. 997-1008.

4. H.P.G. Darcy: Les Fontaines Publiques de la Ville de Dijon, Exposition et Application des Principles a Suivre et des Formules a Employer dans les Questions de Distribution D'eau, Victor Dalmont, Paris, 1856.

5. S. Ergun: Chem. Eng. Progr., 1952, vol. 48, pp. 89-94.

6. I.F. Macdonald, M.S. El-Sayed, K. Mow, and F.A.L. Dullien: Ind. Eng. Chem. Fundam., 1979, vol. 18, pp. 199-208.

7. G.W. Jackson and D.F. James: Can. J. Chem. Eng., 1986, vol. 64, pp. 364-73.

8. F.A.L. Dullien: Porous Media. Fluid Transport and Pore Structure, Academic Press, New York, NY, 1979.

9. M. Singh and D.R. Behrendt: Mater. Sci. Eng., 1994, vol. A187, pp. 183-87. 